Research Article

\title{
Research on the Matching of Impact Performance and Collision Coefficient of Hydraulic Rock Drill
}

\author{
Yelin Li 10 \\ Hunan Province Cooperative Innovation Centre for the Construction \& Development of Dongting Lake Ecological Economic \\ Zone, Hunan University of Arts and Science, Changde 415000, China
}

Correspondence should be addressed to Yelin Li; liyelin0403@aliyun.com

Received 5 October 2020; Revised 3 February 2021; Accepted 27 February 2021; Published 8 March 2021

Academic Editor: Amr A. Nassr

Copyright (c) 2021 Yelin Li. This is an open access article distributed under the Creative Commons Attribution License, which permits unrestricted use, distribution, and reproduction in any medium, provided the original work is properly cited.

The stress wave produced by the piston impact, on the drill rod, is an important factor affecting impact performance. It is particularly important to control the stress waveform generated by the piston impact on the drill rod to meet the requirements of efficiency and component durability of some impact mechanical systems. Based on wave theory, the impact stress wave model of rock drilling is established, a dimensionless collision coefficient $\gamma$ is put forward, and the matching relationship between different collision coefficients $\gamma$ and stress waveforms is analysed. The length of the impact piston under the same material condition determines the change rule of the waveform. The stress waveform experimental verification is thus designed. The pressure chamber curves of different pistons in the rock drill were tested, the collision velocity of the piston was obtained, and the impact energy and impact power were calculated. The relationship between the impact performance and the collision coefficient $\gamma$ is analysed. When $\gamma$ is in the range of 9-11, the impact piston's design of a high-power rock drill can be satisfied. When $\gamma$ is in the range of $3 \sim 5$, it is mainly designed for low-power rock drills.

\section{Introduction}

As drilling equipment, rock drills are widely used in mining, tunnel excavation, urban construction, slag removal, and other operations. Because of its economic, flexible, and wide adaptability to the digging object, rock drills have become the main construction equipment of these projects. Among them, the impact ability of the impact system affects the service durability of the body structure, sealing ring, and connecting bolt. In order to effectively guarantee the continuous working ability of the hydraulic rock drill, more and more scholars pay attention to the research on the relationship between the impact performance of the rock drill and the service durability of its components [1-3].

Under the action of hydraulic pressure, the piston of the rock drill impacts the drill rod at a certain speed and breaks the rock through the drill rod and the drill bit. At the same time, the hydraulic motor of the rock drill drives the drill bit to rotate and break the rock. The rock cuttings are discharged by using flushing water or air. Under the action of propulsion provided by the hydraulic cylinder, the drill continuously impacts, rotates, and discharges rock cuttings to form the blast hole $[4,5]$. The working principle is shown in Figure 1.

Zhai [6] studied the rock fragmentation process of single disc and double disc cutters under no confining pressure. The fracture zone, crack initiation and propagation, and rock fragmentation obtained are identical with the previous experimental and numerical results. Hu [7] compiled a programme interface to simulate the impact performance of rock drills and verified the simulation model by stress wave experiment. Yang [8] built a numerical model of the hydraulic rock drill impact system by using a bond graph method and optimised the key structural parameters. Hashiba [9] simulated the impact process of the rock drill based on the one-dimensional wave theory and researched the dynamic drilling characteristics by using the two-point strain measurement method. The drilling force-depth curves obtained by both experiment and simulation are in good agreement. Kahraman [10] calculated the impact drilling 
efficiency by analysing the axial compression force, Brazilian tensile strength, point bearing strength, and other parameters. Saksala [11] used the finite element modelling method to simulate the impact drilling process of rock drills. Bong Jo Ryu [12] analysed the dynamic response of the elastic impact of the cantilever beam and adjusted its rigid flexible coupling by changing the mechanical structure of the cantilever beam to ensure that the system reaches the optimal state. Le Chiang [13] researched the interaction between rock and bit, put forward the theory of impulse momentum, and solved the problem of one-dimensional waves. Gary [14] superimposed the excitation signal in the impactor control system on the propulsion system and obtained the modulation signal from the rotating torque, so that the impactor has a feedback function. Nygren [15] carried out a series of research on the propagation law of stress waves, stress waveforms, and the transmission efficiency of shock energy in the shock system. Dante [16] systematically studied the propagation of stress waves in shock mechanical systems.

It can be seen from the above analysis that in the hydraulic rock drill, the parts collide with each other, such as piston, shank, and drill rod, in the direction of impact and the axial dimension is far larger than the radial dimension, so it is not appropriate to simplify them as mass points by using classical collision theory. A large volume of scientific research shows that the impact problem in the impact mechanical system can only obtain satisfactory results by applying the wave theory.

Based on the theory of wave mechanics, the wave mechanics model of impact piston impacting drill rods is established. Based on the stress wave testing technology, the stress wave curves of different length impact pistons are tested and the impact performance is calculated. The relationship between impact power and collision coefficient is obtained, which provides a theoretical basis for structural design, optimization, and energy efficiency evaluation of hydraulic rock drills.

\section{Stress Wave Model and Collision Coefficient}

2.1. Stress Wave Model. Indirect impact between the impact piston and drill rod has been widely used in rock drills, and the drill tail is generally used as the spacing part. In the research, a linear spring is generally used to simulate such mechanical properties. The linear spring corresponds to the shank, as shown in Figure 2.

According to the principle of impact, the indirect impact model of impact piston and drill rod is established.

$$
\left\{\begin{array}{l}
\frac{d F}{d t}=k\left(v_{p}-v_{d}\right), \\
v_{d}=\frac{F}{Z_{d}}
\end{array}\right.
$$

where $F$ is the force between the impact piston and the drill rod, $k$ is the equivalent spring stiffness, $v_{p}$ is the impact piston speed, $v_{d}$ is the drill rod speed, and $Z_{d}$ is the wave resistance of the drill rod.
Combining equation (1), we obtain

$$
\frac{d F}{d t}+\frac{k F}{Z_{d}}=k v_{p}
$$

The one-dimensional wave equation can be described by the superposition of forward and reverse waves, both of which are functions of position and time.

$$
\begin{aligned}
& F=M+N, \\
& v=\frac{M-N}{Z},
\end{aligned}
$$

where $M$ is a forward wave, $N$ is an inverse wave, $v$ is a velocity, and $Z$ is a wave resistance.

Substituting equation (2) into equation (4) can obtain the speed of the impact piston as follows:

$$
v_{p}=\frac{1}{Z_{p}}\left(2 M_{p}-F\right),
$$

where $Z_{p}$ is the wave resistance of the impact piston and $M_{p}$ is the forward wave generated by the impact of the impact piston.

Substituting equation (5) into equation (2), we can obtain

$$
\frac{d F}{d t}+k\left(\frac{1}{Z_{p}}+\frac{1}{Z_{d}}\right) F=\frac{2 k}{Z_{p}} M_{p} .
$$

Because the generation of the forward and reverse waves is relative to the impact piston, the impact piston is similar to the drill rod in two materials, and the angle marks $p$ and $d$ of $M$ and $N$ are removed, the forward and reverse waves in the impact piston and drill rod are combined and the forward waves in the $t_{p}$ time period can be obtained as follows:

$$
M_{0}(t)=\frac{1}{2} Z_{p} v_{0} \quad 0 \leq t \leq t_{p},
$$

where $t_{p}$ is the pulse duration of stress wave produced by the impact piston and $v_{0}$ is the initial velocity of the impact piston as shown in Figure 2.

According to formula (3), the inverse wave formed by reflection is as follows:

$$
N_{0}(t)=F_{0}(t)-M_{0}(t) \quad 0 \leq t \leq t_{p} .
$$

After the time of $t_{p} / 2$, the nonimpact surface of the impact piston reflects as a forward wave and then returns:

$$
\begin{cases}M_{1}(t)=-N_{0}\left(t-t_{p}\right), & t_{p} \leq t \leq 2 t_{p}, \\ M_{1}(t)=M_{0}\left(t-t_{p}\right)-F_{0}\left(t-t_{p}\right), & t_{p} \leq t \leq 2 t_{p} .\end{cases}
$$

The above equation is written in general form as follows:

$$
M_{n}(t)=M_{n-1}\left(t-t_{p}\right)-F_{n-1}\left(t-t_{p}\right) \quad n t \leq t \leq(n+1) t_{p}
$$

where $n$ is taken as $1,2,3$. .

Substituting equation (10) into equation (6), we can obtain 


$$
\frac{d F_{n}(t)}{d t}+k\left(\frac{1}{Z_{p}}+\frac{1}{Z_{d}}\right) F_{n}(t)=\frac{2 k}{Z_{p}}\left[M_{n-1}\left(t-t_{p}\right)-F_{n-1}\left(t-t_{p}\right)\right] .
$$

Since the material of an impact piston and drill rod has similar wave resistance, suppose $Z_{p}=Z_{d}=Z$ and initial condition $v_{0}=0$ and substitute equation (7) into equation (6) in $t_{p}$ time period; the solution can be obtained as follows:

$$
F_{0}=\frac{1}{2} Z v_{0}\left(1-e^{-\frac{2 k}{Z} t}\right) \quad 0 \leq t \leq t_{p} .
$$

Under the same conditions, substituting formulas (7) and (12) into formula (11), we can obtain

$$
\frac{d F_{1}}{d t}+\frac{2 k}{Z} F_{1}=Z v_{0} e^{-\frac{2 k}{Z} t} .
$$

The solution is as follows:

$$
F_{1}=\frac{1}{2} Z v_{0}\left[\frac{2 k}{Z} e^{\frac{2 k t_{p}}{Z}} t+\left(1-\frac{2 k}{Z} t_{p}\right) e^{\frac{2 k t_{p}}{Z}}-1\right] \cdot e^{-\frac{2 k t}{Z}} \quad t_{p} \leq t \leq 2 t_{p} .
$$

The stress wave shape formed by impact can be expressed using formula (12) and formula (14).

\subsection{Analysis of the Collision Coefficient and Its Influencing} Factors. For the convenience of research, dimensionless collision coefficient $\gamma=2 k t / Z$ is introduced. In this way, formula (12) and formula (14) can be rewritten as follows:

$$
\frac{F}{Z v_{0}}= \begin{cases}\frac{1}{2}\left(1-e^{-\gamma \frac{t}{t_{p}}}\right), & 0 \leq t^{\prime} \leq 1, \\ \frac{1}{2}\left[\gamma e^{\gamma} \frac{t}{t_{p}}+\left(1-\gamma t_{p}\right) e^{\gamma}-1\right] \cdot e^{-\gamma \frac{t}{t_{p}},} & 1<t^{\prime} \leq 2 .\end{cases}
$$

In the collision coefficient $\gamma=2 k t_{p} / Z, k$ and $Z$ are the material characteristics and easy to analyse, but $t_{p}$ is difficult to quantify in the analysis, so it needs to be analysed after conversion.

$$
\left\{\begin{array}{l}
t_{p}=\frac{2 L}{c}, \\
Z=\rho c A
\end{array}\right.
$$

where $L$ is the length of the impact piston, $c$ is the wave velocity, $\rho$ is the density, and $A$ is the average cross-sectional area of the impact piston.

After formula (16) is put into the formula $\gamma$, the following can be obtained:

$$
\gamma=\frac{2 k t_{p}}{Z}=\frac{2 m_{p} k}{Z^{2}},
$$

where $m_{p}$ is the mass of the impact piston, $m_{p}=\rho L A$.

Using a Matlab tool, draw the stress waveform under different collision coefficients, as shown in Figure 3.

As can be seen in Figure 3, the larger the $\gamma$, the smaller the waveform change and the smaller the $\gamma$, the greater the waveform change. In the case of the same material, $Z$ and $k$ do not change and the size of $m$ determines the size of the waveform change. From formula (17), it can be seen that when $Z$ and $k$ are in the same rock drill, the main factor influencing $m$ is the length $L$ of the impact piston.

In order to verify the correctness of the model and conclusions, a stress wave test is carried out to verify them.

\section{Stress Wave Testing}

The experimental testing system is divided into two parts: stress calibration and stress wave test. By testing impact pistons of different lengths, the matching relationship between collision coefficient and waveform is analysed.

3.1. Stress Calibration. As the test system is affected by many conditions, calibration is an important means to ensure the test accuracy. The specific operating principle is shown in Figure 4. After lifting the impact piston to a certain height, let it fall freely and strike the rod of an energy absorber. The vibration of the measuring rod, the change of internal resistance of strain gauge, and the signal are transmitted to the data acquisition system and then sent to the computer for data processing. After several measurements, the best fitting is obtained and the calibration is completed.

The stress calibration factor is expressed as

$$
B_{s}=\frac{\sigma_{\max }}{n_{\max }}
$$

where $B_{s}$ is the stress calibration factor, $\sigma_{\max }$ is the maximum stress, and $n_{\max }$ is the quantitative value of the peak stress wave sampling point.

From the calibration coefficient, it can be determined that the maximum stress of the brazing $\operatorname{rod}$ is $\sigma_{\max }=B_{\mathrm{s}} \cdot n_{\max }$.

3.2. Stress Wave Testing. After calibration, the rock drill, rod, and energy absorber are installed on a horizontal bench feed cylinder to exert force on the rock drill as shown in Figure 5. The measuring rod needs sufficient length to accurately capture the incident stress waveform and to avoid the interference of reflected waves; one end of the rod is placed in an energy absorbing device. The energy absorber adopts a long tube structure with a built-in friction plate and energy absorbent material, which simulates the continuous energy absorption in the actual work process, eliminates excessive vibration of the rod, and improves the service durability of the strain gauge.

The maximum stress, impact energy, impact frequency, and their statistical values of 25 consecutive impacts were obtained. According to the sampling curve of the average 


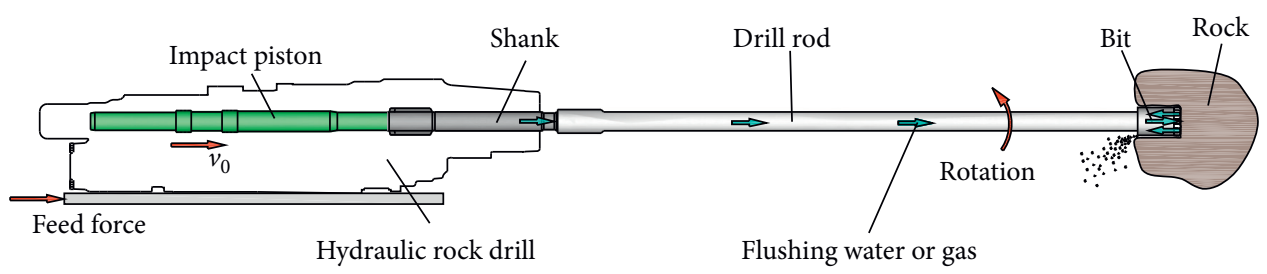

FIGURE 1: Working principle of rock drill.

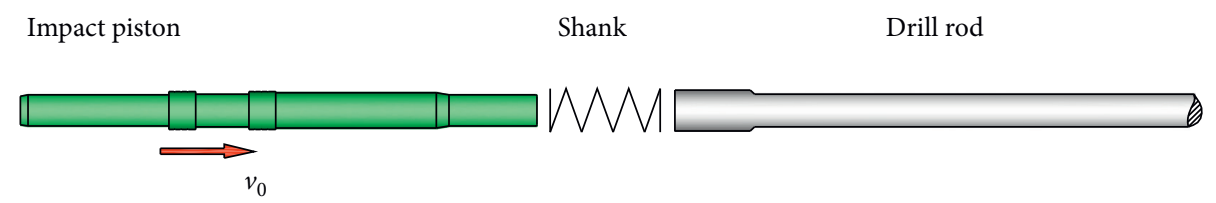

Figure 2: Equivalent mechanical model of an impact piston impacting drill rod.

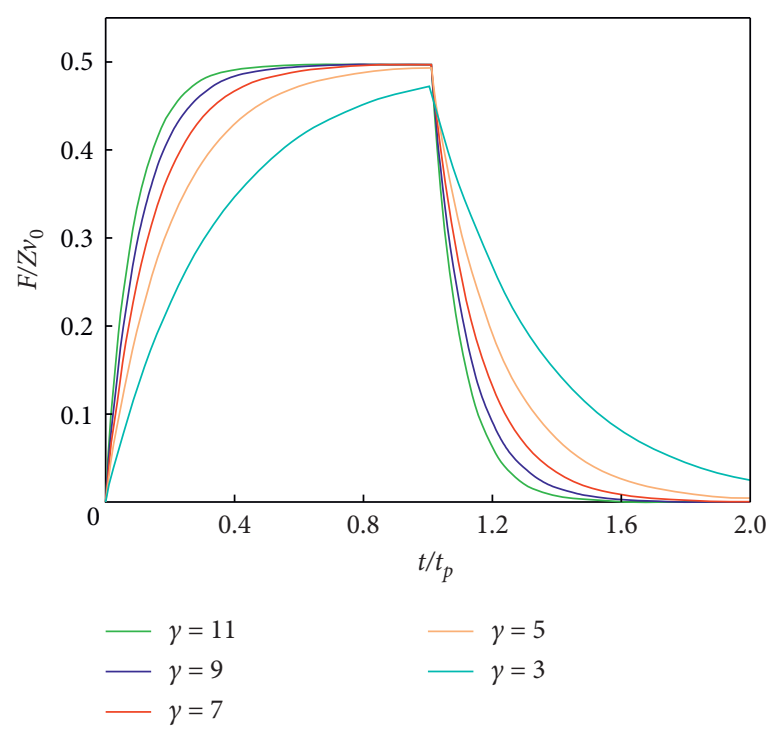

FIGURE 3: Relation between different collision coefficients and shock stress waves.

stress waveform, the maximum stress $\sigma_{\max }$ is calculated as follows:

$$
\sigma_{\max }=\varphi \frac{E}{c} \sqrt{2 g h}
$$

where $E$ is the elastic modulus, $g$ is the acceleration of gravity, $h$ is the falling height when the impact piston is calibrated, and $\varphi$ is the stress coefficient.

\subsection{Stress Wave Matching of Pistons with Different Collision} Coefficients and Parameters. Select three groups of impact pistons with different lengths as shown in Figure 6, and see Table 1 for specific parameters.

It can be seen that the shape of stress wave produced by impact pistons with different lengths and masses is different. The stress wave of No. 1 and No. 2 pistons with longer length and larger mass changes is closer to rectangular wave, with larger peak value, which can produce stronger impact force. The wave shape of No. 3 piston with shorter length and smaller mass changes more smoothly, and the impact force produced by comparing No. 1 piston with No. 2 piston is smaller.

Overlay the test curve and simulation curve in the same diagram for comparative analysis. For ease of analysis, the stress waveforms are divided into loading section (left side) and unloading section (right side), as shown in Figure 8.

It can be seen from the test curve that formula (15) can well express the stress waveform, which is very close to the test results. The waveform of No. 1 piston is distributed in the range of $\gamma=9 \sim 11$, the waveform of No. 2 piston is distributed in the range of $\gamma=5 \sim 9$, and the waveform of No. 3 piston is distributed in the range of $\gamma=3 \sim 5$. The variation rule of stress wave loading section is consistent with the large value change in the selected $\gamma$ 


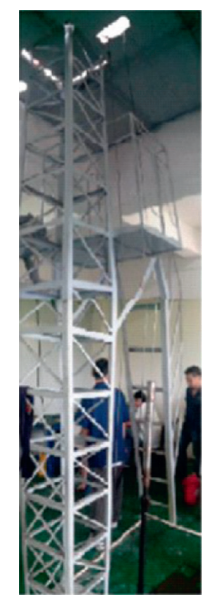

Vertical platform

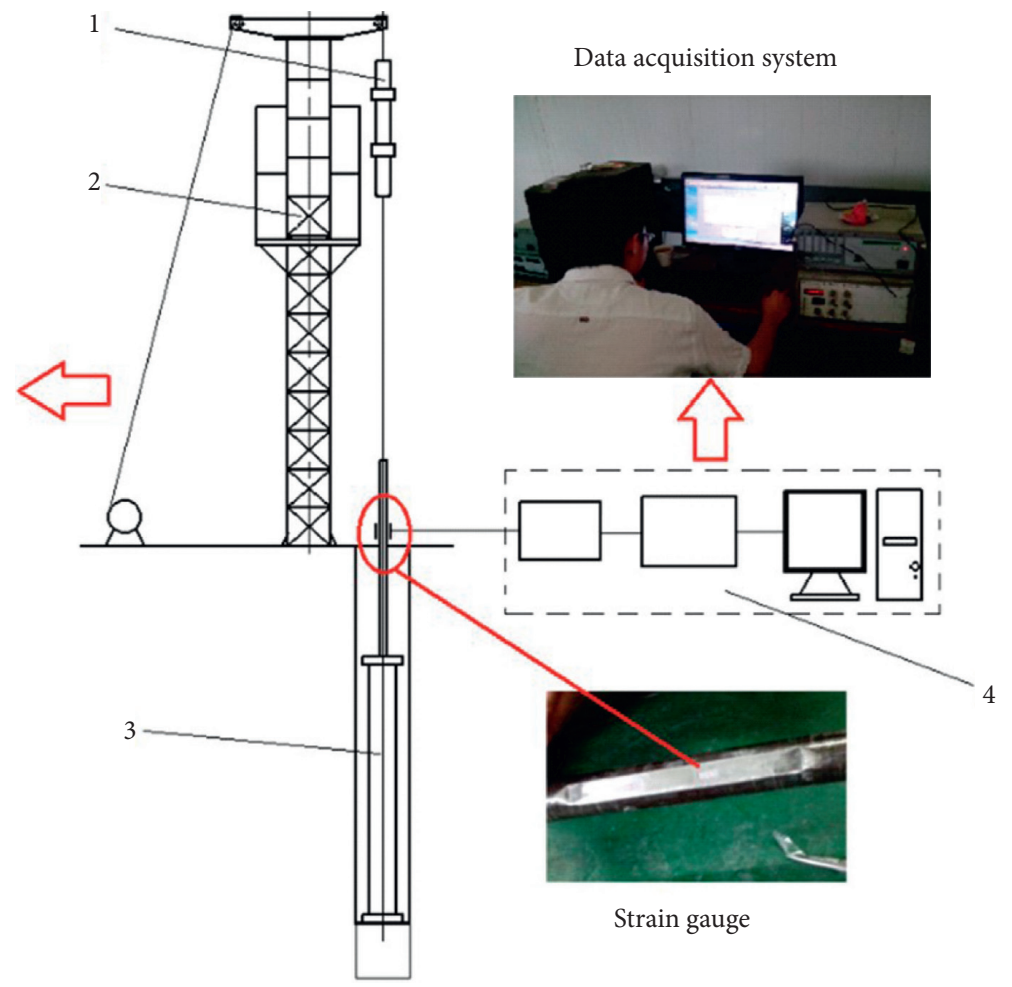

FIGURE 4: Stress calibration experiment. 1-impact piston; 2-vertical platform; 3-energy absorber; 4-data acquisition system.

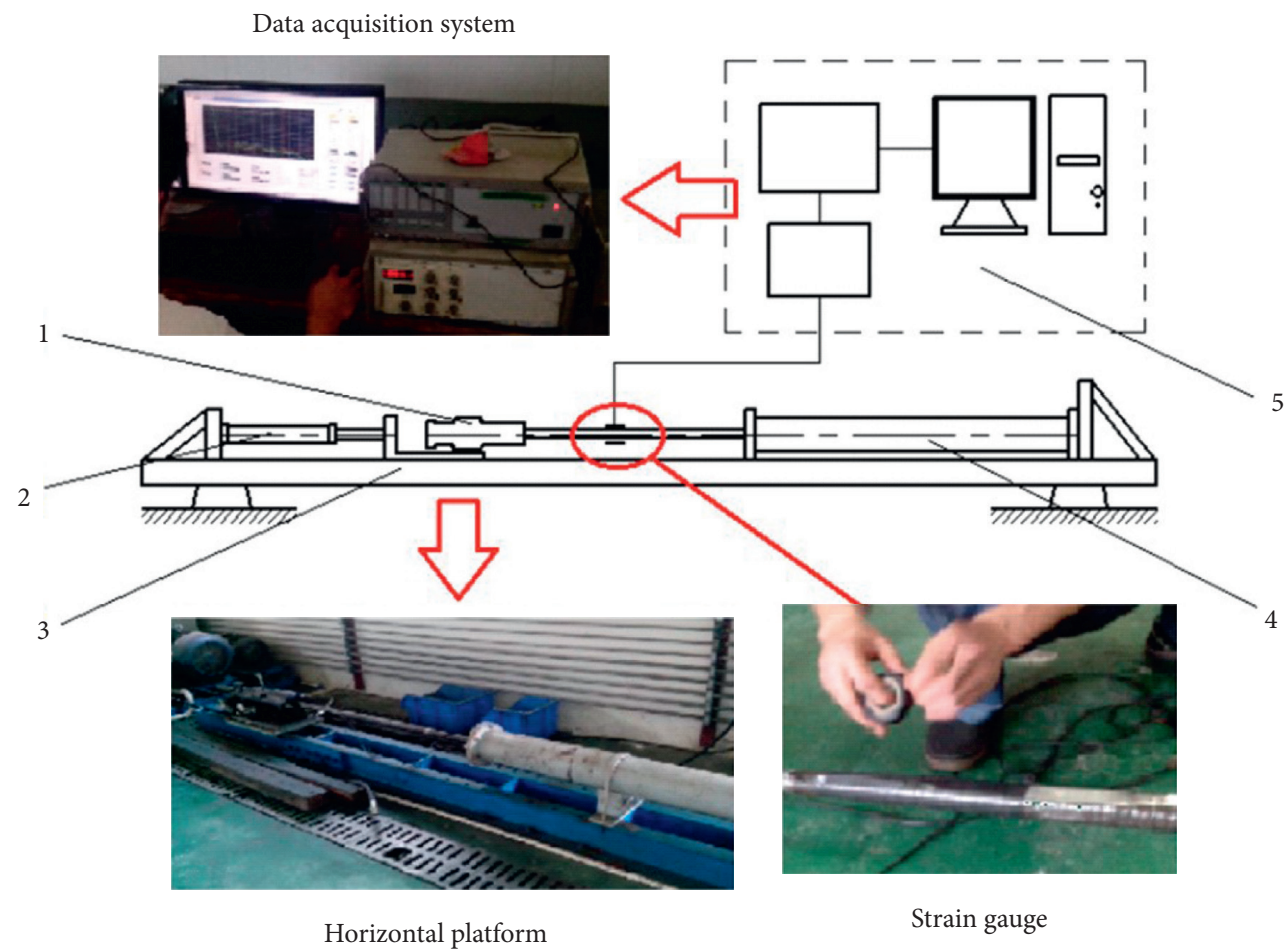

Figure 5: Stress wave testing. 1-rock drill; 2-feed; 3-horizontal platform; 4-energy absorber; 5-data acquisition system. 


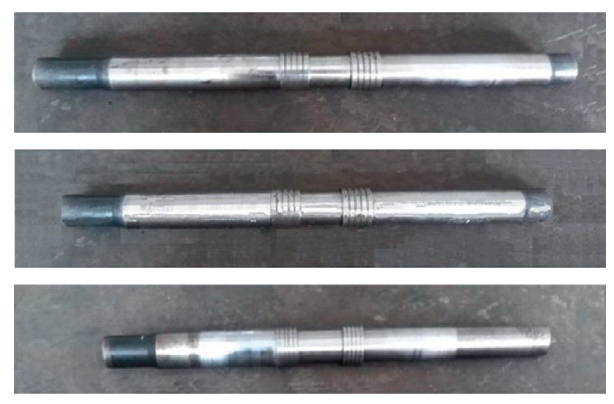

Figure 6: Impact pistons of different lengths.

TABLE 1: Parameters of the tested impact piston.

\begin{tabular}{lcr}
\hline No. & Length $(\mathrm{mm})$ & Mass $(\mathrm{kg})$ \\
\hline 1 & 675 & 7.81 \\
2 & 620 & 7.03 \\
3 & 570 & 5.92 \\
\hline
\end{tabular}

The test stress waveform of the three pistons is shown in Figure 7.

interval. The variation rule of unloading section of stress wave is consistent with the change of small value in the selected $\gamma$ interval.

For example, the variation rule of the stress wave loading section of piston No. 1 is consistent with the curve at the time of $\gamma=11$ in the range of $\gamma=9 \sim 11$ and that of unloading section is consistent with that of $\gamma=9$.

It can be seen that the larger the waveform coefficient $\gamma$ is, the longer the corresponding impact piston length is and the greater the mass is. The smaller the collision coefficient $\gamma$ is, the smaller the length of the corresponding impact piston is and the smaller the mass is.

\section{Impact Energy Experiments of Different Pistons}

4.1. Impact Energy Experimental System and Test Curves. As shown in Figures 9 and 10, the test system is mainly composed of hydraulic pump station, feed cylinder, hydraulic drill, drill rod, punching cylinder, data acquisition system, and computer. The hydraulic rock drill is mounted on the guide rail, and the feed cylinder pushes the drill against the punching cylinder through the drill rod. Accumulators are connected to the punching cylinder, and rocks of different hardness can be simulated by adjusting the charge pressure of the accumulator. The pressure sensors are installed on the hydraulic rock drill to collect the pressure signal of the piston chamber. The pressure system is collected into the computer through the data acquisition system.

The impact piston reciprocates in the cylinder under the action of the hydraulic oil in the front and rear chamber. The rock drill has a designed stroke adjustment mechanism in the impact system, which has two gears. When the adjusting bolt rotates at the corresponding angle, the adjustment mechanism changes the stroke of the impact piston by connecting different loops through oil grooves of different lengths, as shown in Figure 11. Due to the different strokes of the impact piston, the corresponding parameters such as impact energy and impact frequency will change accordingly. Short and long stroke data are tested for impact pistons of different lengths.

The initial parameters of the test system are set before the test, mainly the input pressure of the hydraulic system. The specific pressure parameters are shown in Table 2 .

The test results of the front and rear chamber pressure of three groups of impact pistons under the condition of long stroke are shown in Figure 12. In order to analyse the motion law of the impact piston, the timing of the impact piston impacting on the drill rod is key. First of all, before the impact piston impacts the drill rod, the pressure in the rear chamber is greater than that in the front chamber and the stroke speed of the impact piston is increasingly fast. At this time, the pressure in the rear chamber will continue to drop. As the impact piston moves forward with the drill rod during the impact, the rear chamber space will be increased a little, resulting in a rapid drop in pressure. When the impact piston and drill rod stop moving, there will be a peak pressure. The local enlarged view in Figure 12 clearly shows the pressure change in the rear chamber at the time of impact. It can be seen that the peak pressure produced by the impact of No. 1 piston is larger than that of No. 3 piston. This is due to the impact force on the piston.

Under the condition of a long stroke, the movement period of No. 3 piston is short, one period is about $23 \mathrm{~ms}$, and the peak value of reversing and impact is about $35 \sim 37 \mathrm{MPa}$. The movement period of No. 1 piston is long, one period is about $28 \mathrm{~ms}$, and the peak value of reversing and impact is about $44 \sim 47 \mathrm{MPa}$. The test data of No. 2 piston are moderate, which are $25 \mathrm{~ms}$ and $40 \sim 42 \mathrm{MPa}$, respectively.

As shown in Figure 13, the test results under the condition of a short stroke are similar to those under the condition of a long stroke, but the pressure peaks corresponding to the three groups of data are reduced and the movement period of the impact piston is shortened. The movement period of No. 3 piston is about $21 \mathrm{~ms}$, and the 
peak value of reversing and impact is about $34 \sim 35 \mathrm{MPa}$. The movement period of No. 1 piston is about $25 \mathrm{~ms}$, and the peak value of reversing and impact is about $40 \sim 44 \mathrm{MPa}$. The test data of No. 2 piston are moderate, which are $23 \mathrm{~ms}$ and 37 40 MPa, respectively.

4.2. Impact Energy Calculation. The pressure curve is integrated through the position of the impact point; the velocity of the impact process is obtained from

$$
F t=m v,
$$

where $F$ is the action force of oil pressure on the impact piston in the stroke process, $t$ is the action time of the impact piston, $m$ is the mass of the impact piston, and $v$ is the velocity of the impact piston.

The action force of oil pressure on the impact piston during rock drilling is shown in Figure 11. The impact piston is reciprocating in the cylinder, under the pressure of hydraulic oil in the front and rear chambers. The action force $(F)$ can be expressed by

$$
F=P_{1} A_{1}-P_{2} A_{2}
$$

where $P_{1}$ is the front chamber pressure, $P_{2}$ is the rear chamber pressure, $A_{1}$ is the effective working area of the rear chamber of the impact piston, and $A_{2}$ is the effective working area of the back chamber of the impact piston.

The action force $F$ acting on the impact piston is integrated.

$$
\int_{a i}^{b i} F d t=m v .
$$

Formula (21) is substituted in formula (22).

$$
\int_{a i}^{b i}\left(P_{1} A_{1}-P_{2} A_{2}\right) d t=m v .
$$

The speed of each moment is obtained in formula (24).

$$
v_{i}=\frac{A_{1} \int_{a i}^{b i} P_{1} d t-A_{2} \int_{a i}^{b i} P_{2} d t}{m} .
$$

The displacement curve formula (25) of impact piston is obtained by integrating the velocity curve.

$$
S=\int_{a i}^{b i} v d t
$$

where $S$ is the displacement of the impact piston.

Under the condition of a long stroke, the velocity and displacement curves of three groups of impact pistons obtained by integrating the impact pressure are shown in Figure 14. Because of the reciprocating motion of the impact piston, the velocity direction will change. The positive direction represents the direction of return and deceleration, and the negative direction represents the direction of stroke. For the convenience of analysis, the impact point is defined as the starting point of piston motion. After the impact of the impact piston, the speed decreases rapidly from the maximum value to 0 . Because the impact will rebound, the rebound speed will occur at the impact time. The rebound speed makes the piston have better power to carry out the next reciprocating motion. The rebound effect of the three groups of pistons can be clearly seen in the partial enlarged figure of Figure 14.

Under the condition of a long stroke, as shown in Figure 14 , the impact point velocity $v_{\max }$ of No. 1 piston is $12.1 \mathrm{~m} / \mathrm{s}$, and that of No. 2 piston is $11.3 \mathrm{~m} / \mathrm{s}$ and No. 3 piston is $10.1 \mathrm{~m} / \mathrm{s}$. The rebound speed of No. 1 piston is $1.5 \mathrm{~m} / \mathrm{s}$, and that of No. 2 piston is $1.2 \mathrm{~m} / \mathrm{s}$ and No. 3 piston is $0.8 \mathrm{~m} / \mathrm{s}$. The displacement of No. 1 piston is $57 \mathrm{~mm}$, No. 2 piston is $50 \mathrm{~mm}$, and No. 3 piston is $48 \mathrm{~mm}$.

Under the condition of a short stroke, as shown in Figure 15 , the impact point velocity $v_{\max }$ of No. 1 piston is $10 \mathrm{~m} / \mathrm{s}$, and that of No. 2 piston is $9.1 \mathrm{~m} / \mathrm{s}$ and No. 3 piston is $8.3 \mathrm{~m} / \mathrm{s}$. The rebound speed of No. 1 piston is $1.3 \mathrm{~m} / \mathrm{s}$, and that of No. 2 piston is $0.9 \mathrm{~m} / \mathrm{s}$ and No. 3 piston is $0.6 \mathrm{~m} / \mathrm{s}$. The displacement of No. 1 piston is $50 \mathrm{~mm}$, and that of No. 2 piston is $45 \mathrm{~mm}$ and No. 3 piston is $41 \mathrm{~mm}$. Compared with the long stroke condition, the stroke of the impact piston becomes shorter, the velocity becomes smaller, and the period becomes shorter.

The maximum impact energy is obtained when the velocity is maximum, so the impact energy can be obtained by

$$
E_{p}=\frac{1}{2} m v_{\max }^{2}
$$

where $E_{p}$ is the impact energy.

\section{Analysis of the Relationship between Impact Performance and $\gamma$}

The impact power can be calculated by impact energy and impact frequency. The impact energy is the calculated value, and the impact frequency is the measured value. The impact power can be obtained by

$$
W_{p}=E_{p} \cdot f
$$

where $W_{p}$ is the impact power and $f$ is the impact frequency.

According to the initial pressure and flow rate of the experimental system, the input power of the impact system of the rock drill can be obtained byfd 28

$$
W_{d}=\overline{P_{d}} \cdot \frac{\overline{Q_{d}}}{60},
$$

where $W_{d}$ is the input power, $P_{d}$ is the working pressure, and $Q_{d}$ is the working flow.

In Table 3, the relevant data of test and simulation are integrated to analyse the data relationship in different $\gamma$ ranges.

It can be seen from Table 3 that with the increase of the range of $\gamma$, the impact frequency decreases, the impact energy increases, the impact power increases, and the efficiency increases. Because the impact piston works at a higher frequency, the greater the impact energy, the higher the material performance requirements of the impact piston; otherwise, the durability of the impact piston cannot meet 

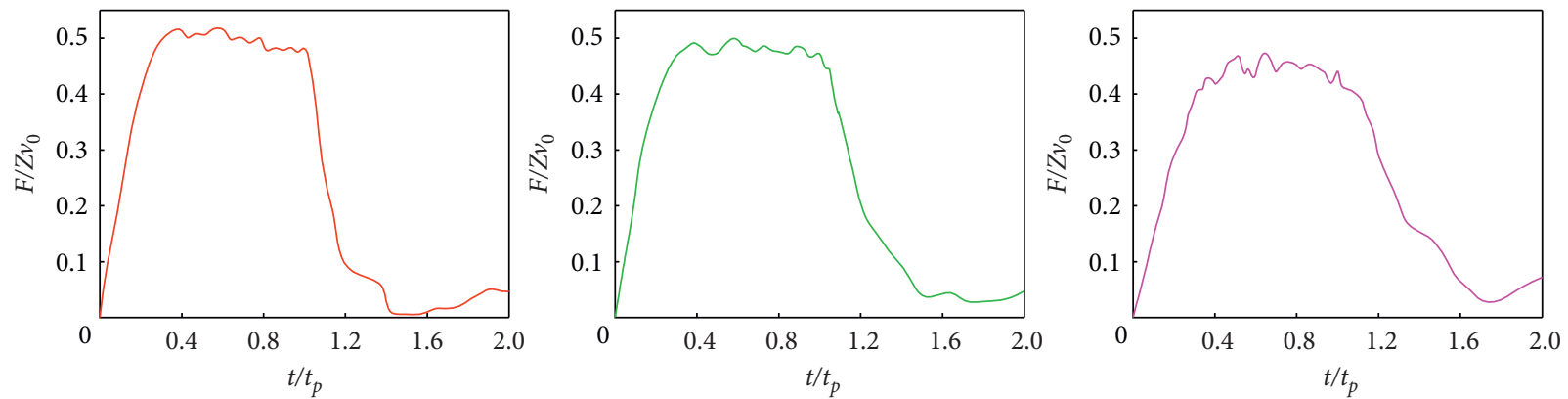

Figure 7: Stress waveform of the impact piston using different parameters. (a) No. 1 piston, $L=675 \mathrm{~mm}$. (b) No. 2 piston, $L=620 \mathrm{~mm}$. (c) No. 3 piston, $L=570 \mathrm{~mm}$.
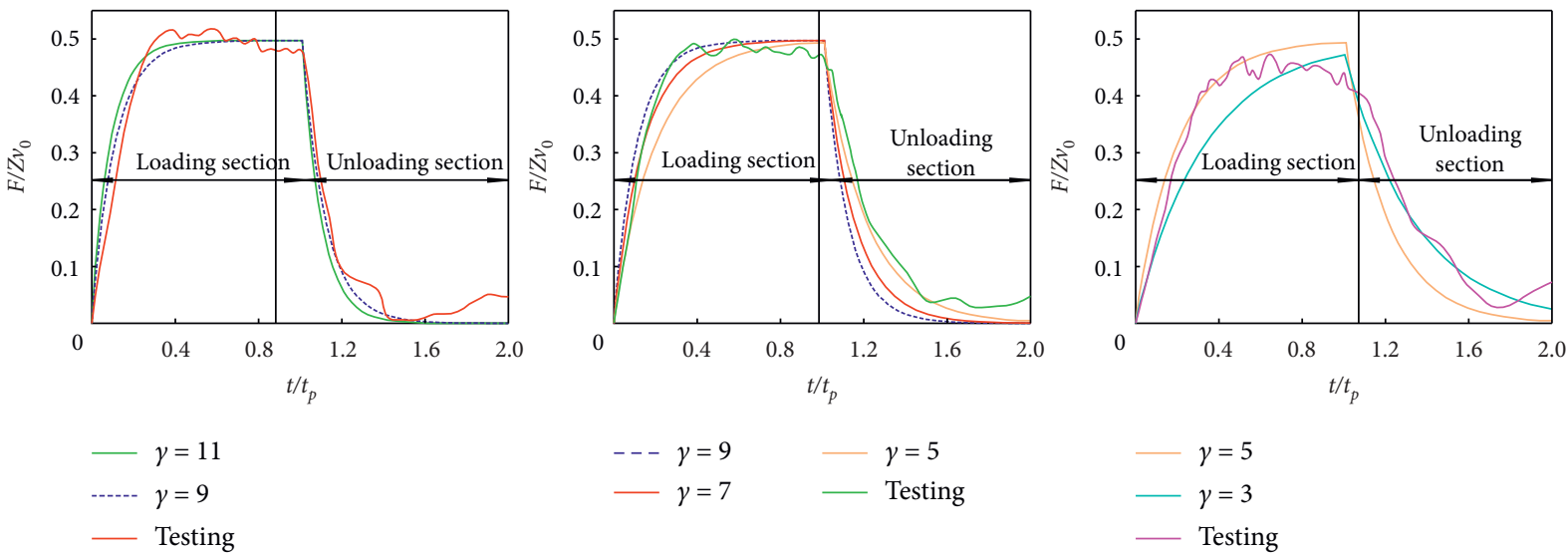

FIGURE 8: Comparison of stress wave experiment and simulation wave of the impact piston using different parameters. (a) No. 1 piston $L=675 \mathrm{~mm}$. (b) No. 2 piston $L=620 \mathrm{~mm}$. (c) No. 3 piston $L=570 \mathrm{~mm}$.

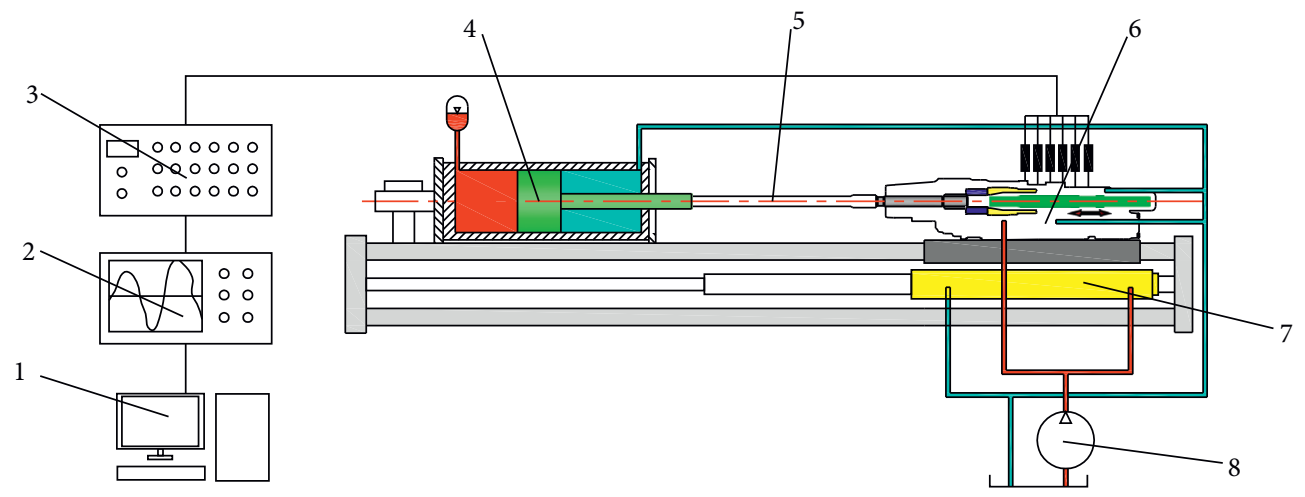

Figure 9: Performance test system of hydraulic rock drill. 1-computer; 2-data acquisition system; 3-signal amplifier; 4-punching cylinder; 5drill rod; 6-hydraulic rock drill; 7-feed cylinder; 8-hydraulic pumping station. 


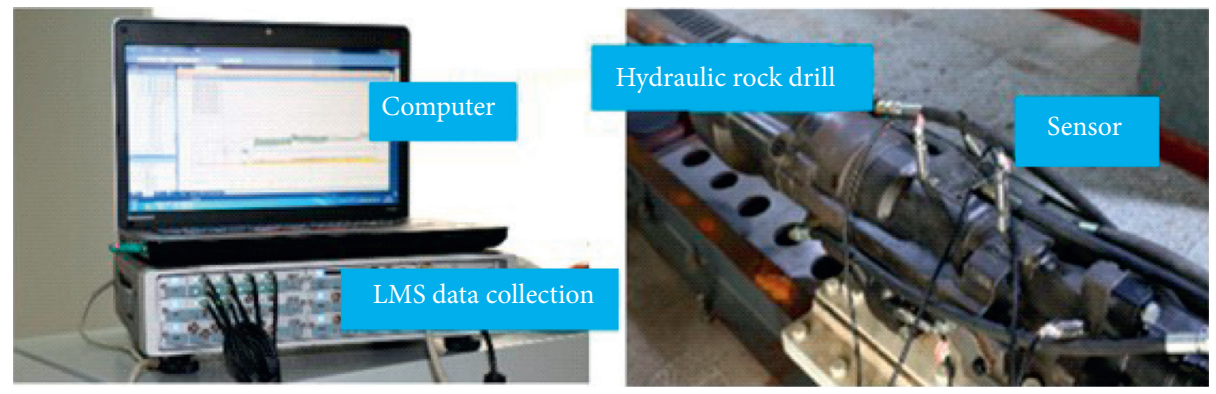

FIGURE 10: Photographs of some equipment of the experimental test system.

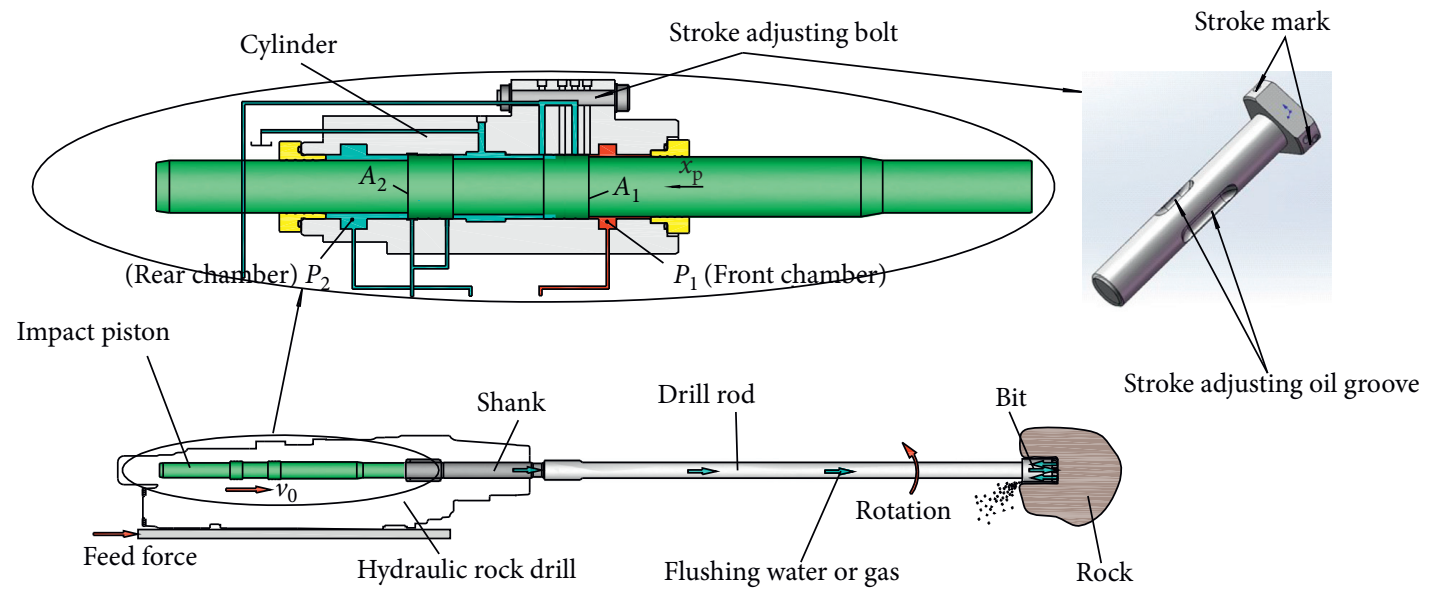

FIGURE 11: Principle of adjusting stroke of impact piston by adjusting bolt.

TABLE 2: Experimental data setting.

\begin{tabular}{lcc}
\hline No. & Data name & Set value (MPa) \\
\hline 1 & Working pressure of rock drilling & 20 \\
2 & Damping system pressure & 3.5 \\
3 & Working pressure of punching cylinder & 10.5 \\
4 & Working pressure of feed cylinder & 3.7 \\
5 & Initial pressure of damping accumulator & 3.5 \\
6 & Initial pressure of high-pressure accumulator & 11.5 \\
\hline
\end{tabular}

the working requirements. For the same group of pistons, except for the decrease of frequency, other parameters will increase under the condition of a long stroke.

When $\gamma$ is in the range of 9 11, the frequency is low and the impact power is high. Because of the long displacement of the piston, the flow required for the impact piston is high and the impact efficiency is high. At this time, the performance of the impact piston is required to be high. It will increase the manufacturing cost of the rock drill.

When $\gamma$ is in the range of $3 \sim 5$, the frequency is high and the impact power is low. Because the displacement of the piston is short, the flow required for the impact piston is small. The impact efficiency is slightly lower. No matter long stroke or short stroke, the impact energy of No. 1 piston is about twice that of No. 3 piston.

When $\gamma$ is in the range of 5 9, all parameters are moderate. The parameters of this interval under the condition of long stroke are close to the parameters of short stroke of No. 1 piston, and the parameters under the condition of short stroke are close to the parameters of long stroke of No. 3 piston.

According to the above analysis, it is suggested to select the interval of 9 11 for the design of high-power heavy rock drill and 3 5 for the design of low-power light rock drill. Because $\gamma$ is in the range of 5 9, all performance parameters have no special characteristics, and there are overlapping 


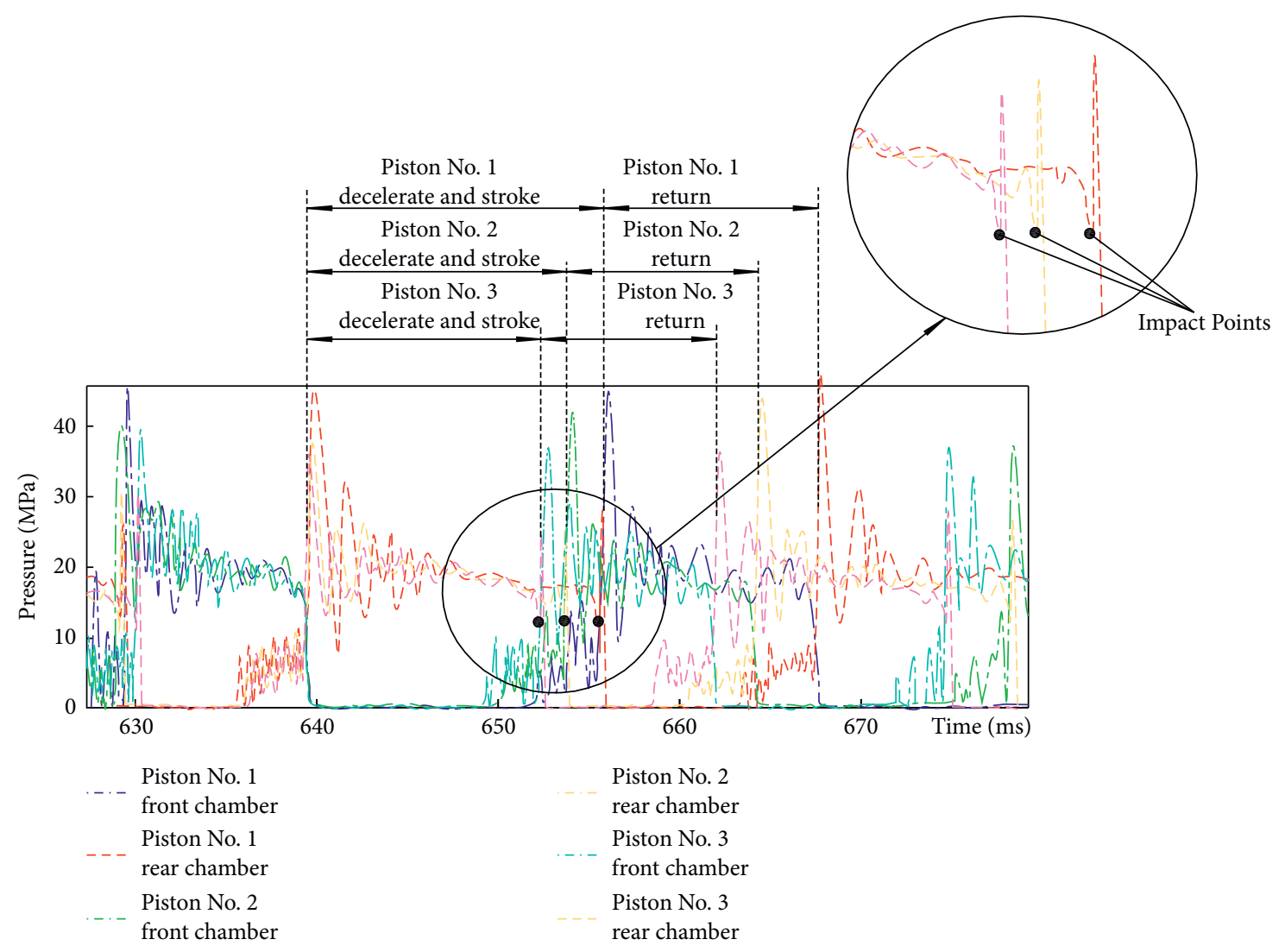

FIGURE 12: Under the condition of a long stroke, the pressure curves of the front and rear chambers of impact pistons with different lengths.

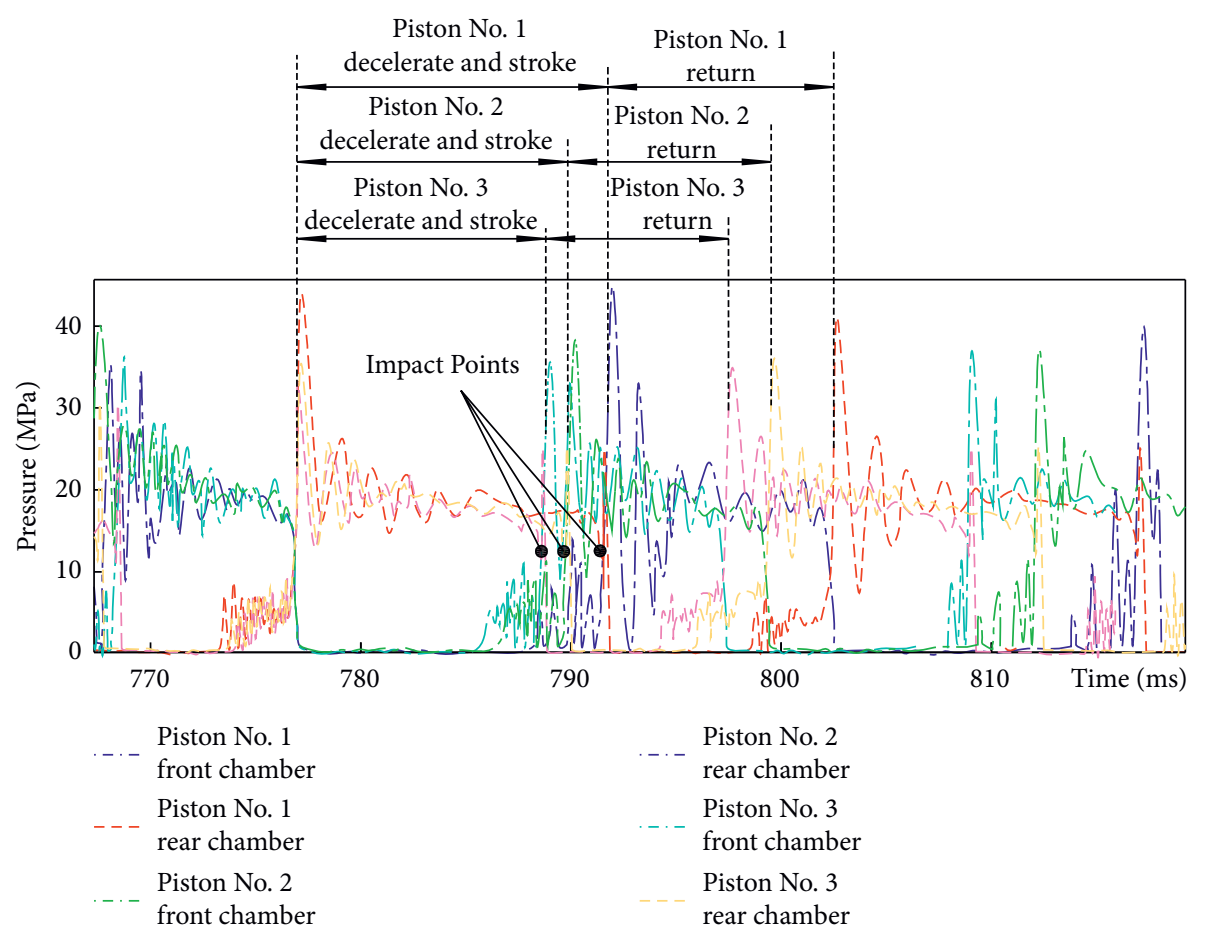

FIGURE 13: Under the condition of a short stroke, the pressure curves of the front and rear chambers of impact pistons with different lengths. 


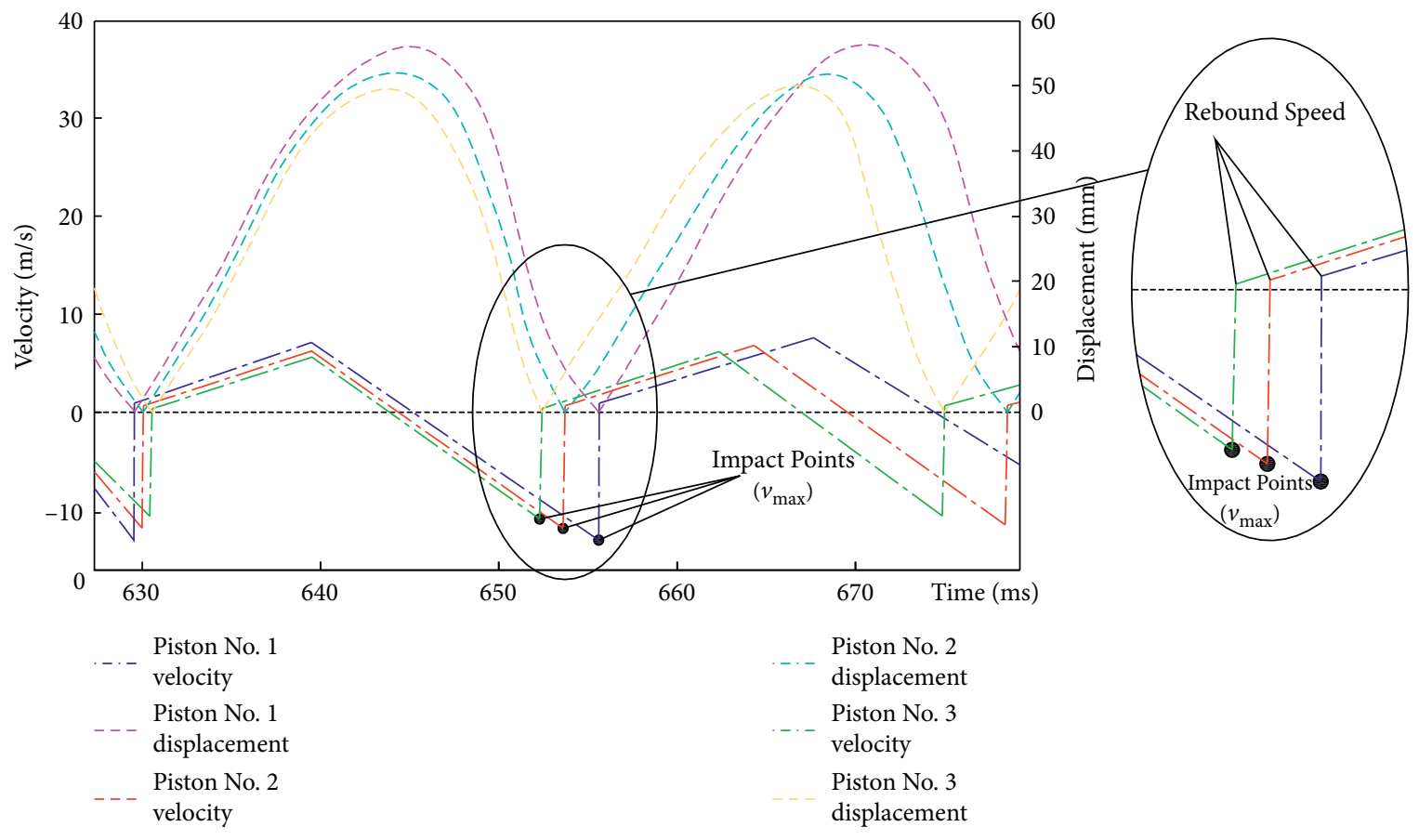

FIGURE 14: Under the condition of a long stroke, the velocity and displacement curves of impact pistons with different lengths.

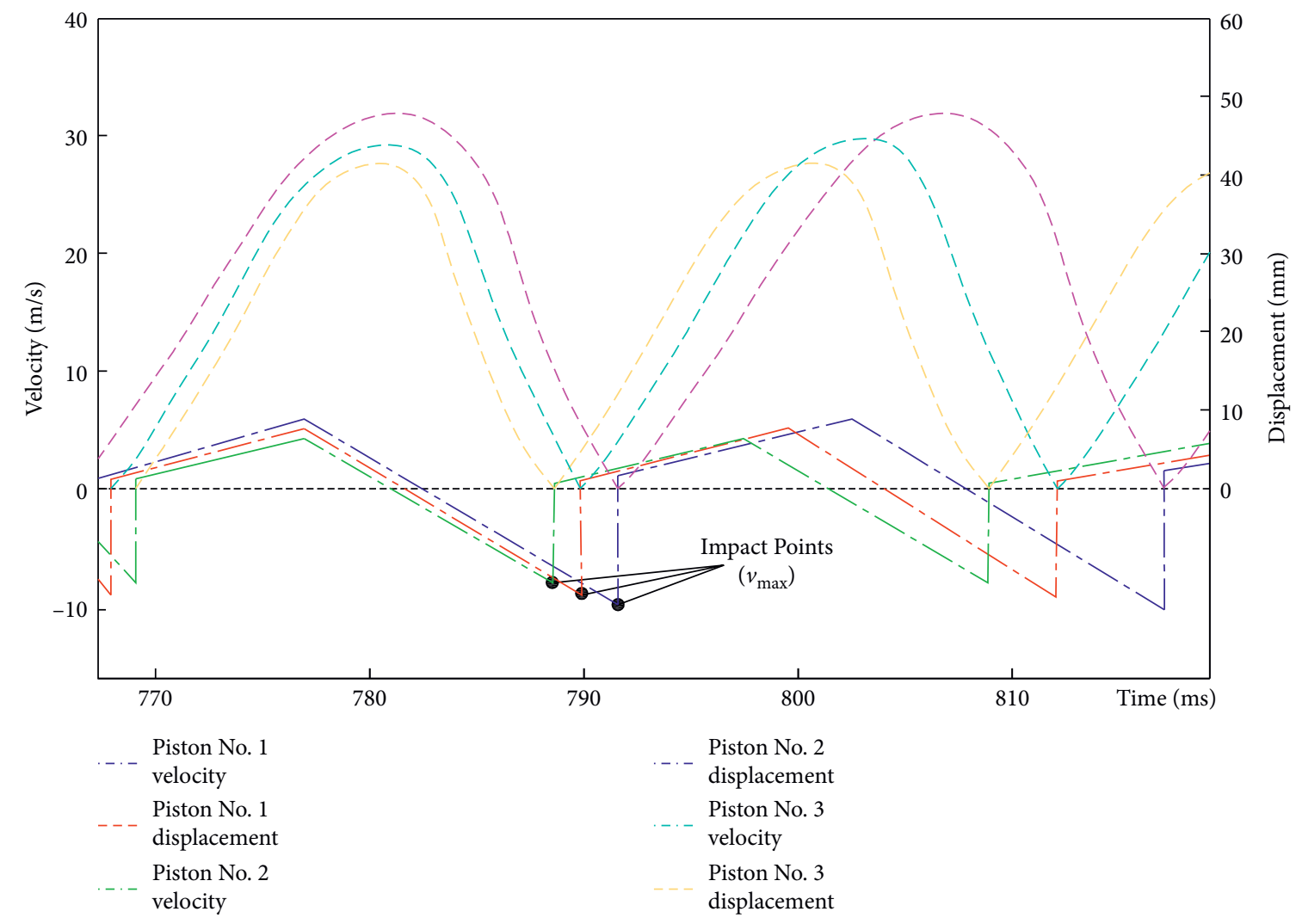

FIGURE 15: Under the condition of a short stroke, the velocity and displacement curves of impact pistons with different lengths. 
TABLE 3: Calculation results of impact energy of the impact piston by different lengths and masses.

\begin{tabular}{lccccccccc}
\hline Piston & $\gamma$ & Stroke & $P_{d}(\mathrm{MPa})$ & $Q_{d}(\mathrm{~L} / \mathrm{min})$ & $W_{d}(\mathrm{~kW})$ & $f(\mathrm{~Hz})$ & $E_{p}(\mathrm{~J})$ & $W p(\mathrm{~kW})$ & Efficiency $(\%)$ \\
\hline \multirow{2}{*}{ No. 1} & \multirow{2}{*}{$9 \sim 11$} & Long & 20 & 93 & 31 & 35.7 & 571.7 & 20.4 & 65.8 \\
& & Short & 20 & 80 & 26.7 & 40 & 390 & 15.6 & 58 \\
No. 2 & \multirow{2}{*}{$5 \sim 9$} & Long & 20 & 83 & 27.7 & 40 & 440.9 & 16.9 & 61 \\
& & Short & 20 & 69 & 23 & 43.5 & 290.1 & 12.6 & 54.8 \\
No. 3 & \multirow{2}{*}{$3 \sim 5$} & Long & 20 & 71 & 23.6 & 43.5 & 301.9 & 13.1 & 55.5 \\
& & Short & 20 & 58 & 19.3 & 47.6 & 203.9 & 9.7 & 50.3 \\
\hline
\end{tabular}

parts with the other two intervals, the value of this range cannot be considered in the design and manufacture of rock drills.

\section{Conclusions}

(1) Based on the theory of wave mechanics, a wave mechanics model of indirect impact is established by simplifying the shank of the middle connecting part between the impact piston and the drill rod as a spring, and the one-dimensional wave equation is described by the superposition of forward and reverse waves. In the stress wave model, for the convenience of research, the dimensionless collision coefficient $\gamma$ is proposed and the parameter $t_{p}$ which cannot be quantified in the collision coefficient $\gamma$ is quantised, and the main influencing factor of $\gamma$ is the length $L$ of the impact piston.

(2) In order to ensure the test accuracy of the stress wave, the stress calibration experiment is carried out. Based on the calibration experiment, the stress wave test experiment is carried out. The average value of 25 tests is taken as the sample of stress waves, and the stress wave curves of different length impact pistons are obtained. By fitting the loading and unloading sections of the stress wave curve with different values of $\gamma$, the relationship between $\gamma$ and three groups of impact pistons with different lengths is obtained.

(3) The impact performance experiments of three groups of pistons under different strokes were designed, and the pressure curves of the front and rear cavities of the three groups of impact pistons were obtained. The peak value of the pressure curve is used to determine the position of the impact point, and the curve is integrated to obtain the velocity and displacement curves. The impact velocity can be obtained by the position of the impact point on the velocity curve, and the impact energy can be obtained by the impact velocity. The related motion period, pressure peak, limit displacement, impact velocity, and other related parameters can also be obtained in the curves of pressure, velocity, and displacement.

(4) The change law of impact performance parameters is analysed when $\gamma$ is 9 11, 3 5, and 5 9. The range of 9 11 has better impact performance and higher working efficiency, which is suitable for the design of high-power heavy rock drill. However, this range requires high performance of the impact piston material, which increases the manufacturing cost. The range of 3 5 has lower impact energy, which is suitable for the design of low-power rock drills. This range requires low performance of the impact piston material. The performance parameters of interval 5 9 coincide with the other two intervals, which can not be considered in design.

\section{Data Availability}

The test data used to support the findings of this study are included within the article.

\section{Conflicts of Interest}

The author declares that there are no conflicts of interest.

\section{Acknowledgments}

This research was sponsored by Education Department Excellent Youth Item of Hunan Province (Grant no. 18B397), Natural Science Foundation of Hunan Province (Grant no. 2019JJ50404), General Project of Changde Science and Technology Bureau (Grant nos. 2019S065 and 2018J051), and Provincial Specialty Disciplines of Higher Education Institutions in Hunan Province (Grant no. XJT [2018] 469).

\section{References}

[1] J. Wang and J. Zhang, "Research on high-power and highspeed hydraulic impact testing machine for mine anti-impact support equipment," Shock and Vibration, vol. 2019, Article ID 6545980, 12 pages, 2019.

[2] L. Gao, C. Jin, Y. Liu, F. Ma, and Z. Feng, "Hybrid modelbased analysis of underground articulated vehicles steering characteristics," Applied Sciences, vol. 9, no. 24, p. 5274, 2019.

[3] H. Jiang, Z. Cai, O. Wang, and D. Meng, "Experimental and numerical investigation of hard rock breakage by indenter impact," Shock and Vibration, vol. 2020, Article ID 2747830, 12 pages, 2020.

[4] M. Fourmeau, A. Kane, and M. Hokka, "Experimental and numerical study of drill bit drop tests on Kuru granite," Philosophical Transactions of the Royal Society A: Mathematical, Physical and Engineering Sciences, vol. 375, no. 2085, Article ID 20160176, 2017.

[5] F. Ren, T. Fang, and X. Cheng, "Study on rock-breaking depth and damage area under particle jet impact," Shock and Vibration, vol. 9, pp. 1-12, 2019. 
[6] S. F. Zhai, S. H. Cao, M. Gao, and Y. Feng, "The effects of confining stress on rock fragmentation by TBM disc cutters," Mathematical Problems in Engineering, vol. 2019, Article ID 5432470, 13 pages, 2019.

[7] Q. Hu, C. Yang, H. Zheng, and M. Chen, "Dynamic simulation and test research of impact performance of hydraulic rock drill with no constant-pressurized chamber," Automation in Construction, vol. 37, no. 1, pp. 211-216, 2014.

[8] S.-Y. Yang, Y.-B. Ou, Y. Guo, and X.-M. Wu, "Analysis and optimization of the working parameters of the impact mechanism of hydraulic rock drill based on a numerical simulation," International Journal of Precision Engineering and Manufacturing, vol. 18, no. 7, pp. 971-977, 2017.

[9] K. Hashiba, K. Fukui, Y. Z. Liang, M. Koizumi, and T. Matsuda, "Force-penetration curves of a button bit generated during impact penetration into rock," International Journal of Impact Engineering, vol. 85, pp. 45-56, 2015.

[10] S. Kahraman, N. Bilgin, and C. Feridunoglu, "Dominant rock properties affecting the penetration rate of percussive drills," International Journal of Rock Mechanics and Mining Sciences, vol. 40, no. 5, pp. 711-723, 2003.

[11] T. Saksala, D. Gomon, M. Hokka, and V.-T. Kuokkala, "Numerical and experimental study of percussive drilling with a triple-button bit on Kuru granite," International Journal of Impact Engineering, vol. 72, pp. 56-66, 2014.

[12] J. R. Bong, H. H. Hyun, S. L. Gyu et al., "Dynamic response analysis of a cantilevered beam due to an elastic impact," International Journal Precision Engineering and Manufacturing, vol. 11, no. 4, pp. 539-547, 2010.

[13] L. E. Chiang and D. A. Elias, "Modeling impact in down-the-hole rock drilling," International Journal of Rock Mechanics and Mining Sciences, vol. 37, no. 4, pp. 599-613, 2000.

[14] L. C. Gary, M. Kochanek, B. C. Jack et al., "A self-optimizing control system for hard rock percussive drilling," Transactions on Mechatronics, vol. 13, no. 4, pp. 153-157, 2008.

[15] T. Nygren, L. E. Andersson, and B. Lundberg, "Optimization of elastic junctions with regard to transmission of wave energy," Wave Motion, vol. 29, no. 5, pp. 223-244.

[16] D. A. Elias and L. E. Chiang, "Dynamic analysis of impact tools by using a method based on stress wave propagation and impulse-momentum principle," Journal of Mechanical Design, vol. 125, no. 3, pp. 131-142, 2003. 